\title{
Reflecting on RTD 2015: Making connections to doing RtD
}

Rebecca Taylor

October 2016

Writing from the perspective of a delegate and early career practice-based researcher $\left(2^{\text {nd }}\right.$ year $\left.\mathrm{PhD}\right)$ this article shares the connections I have made between having experienced the Research Through Design 2015 Conference (RTD) and my experiences of doing Research through Design (RtD).

To provide an example of 'doing RtD' I outline the projects situated at the heart of my doctoral studies. Further to this, I critically examine 'features of experience' and how they have emerged from doing RtD. The aim of this article is to provoke further discussion on the reflective processes of doing RtD and, in doing so, reveal the potential to map and inform the progression and impacts of RtD methodology.

To set the scene, I present two examples of RtD projects. I then organize the article into three sections that pose questions such as, how are we experiencing doing RtD? How do we manage the good and the glory in RtD projects? And, how has RTD inspired the theoretical lens through which to do RtD?

To help navigate the article there are three waves of reflective narrative. I begin by retreating into my practice and present my experiences of doing RtD by providing two examples of RtD projects - 'Have Conversations With...' and 'The Rooftop 
Project'. Both situated in Manchester's City Centre these projects provide the backdrop to my reflective practice. I then introduce my first point of critical reflection of RTD 2015 - '1.0 Designing Experience' - a critical reflection of the composition of RTD 2015 and Nelly Ben Hayoun's opening provocation (RTD 2015 2016). Following this I come forward with a more outwardly facing second point of critical reflection '2.0 Good Vs Glory', inspired by David Gauntlett and Amy Twigger Holroyd's Making and Making a Difference Provocation (RTD 2015 2016). I found the content inspired a deeper inquiry of our responsibility as an RTD community. In the third point of critical reflection '3.0 Materiality \& Sociomateriality' I retreat once more, reflecting on my own practice through experiencing Tim Ingold's closing provocation (RTD 2015 2016). It is here where I introduce the theoretical lens, sociomateriality, through which I position myself as a researcher and where I am prompted to ask further questions of The Rooftop Project.

Albeit messy, making connections by being reflective in my work is, as Judi Marshall says of action research, a process of 'living life as inquiry' ${ }^{1}$. I propose therefore that grappling with applying the ethos of 'living life as inquiry' is pivotal to doing RtD and in this article I invite deeper dialogic interaction on this subject.

\section{Doing Research through Design}

The Rooftop Project emerged as an experimental project responding to the local greening groups, residents and businesses concern for the lack of green, social space 
in Manchester's City Centre. When documenting my process of doing RtD I write detailed reflection entries. However, on occasions I have found myself summarizing my thoughts in a more visual or graphical representation, in what I consider 'an artifact of reflection' (Fig. 1). This image became a point of reference, because in sharing this with the community I was working with, we could nod in agreement and find ways in which we could stop, discuss and reflect commonalities. This also started the visual documentation of 'The Story of The Rooftop Project...' - a visual PDF, which I continue to update and circulate as a way of showing and telling people about The Rooftop Project.

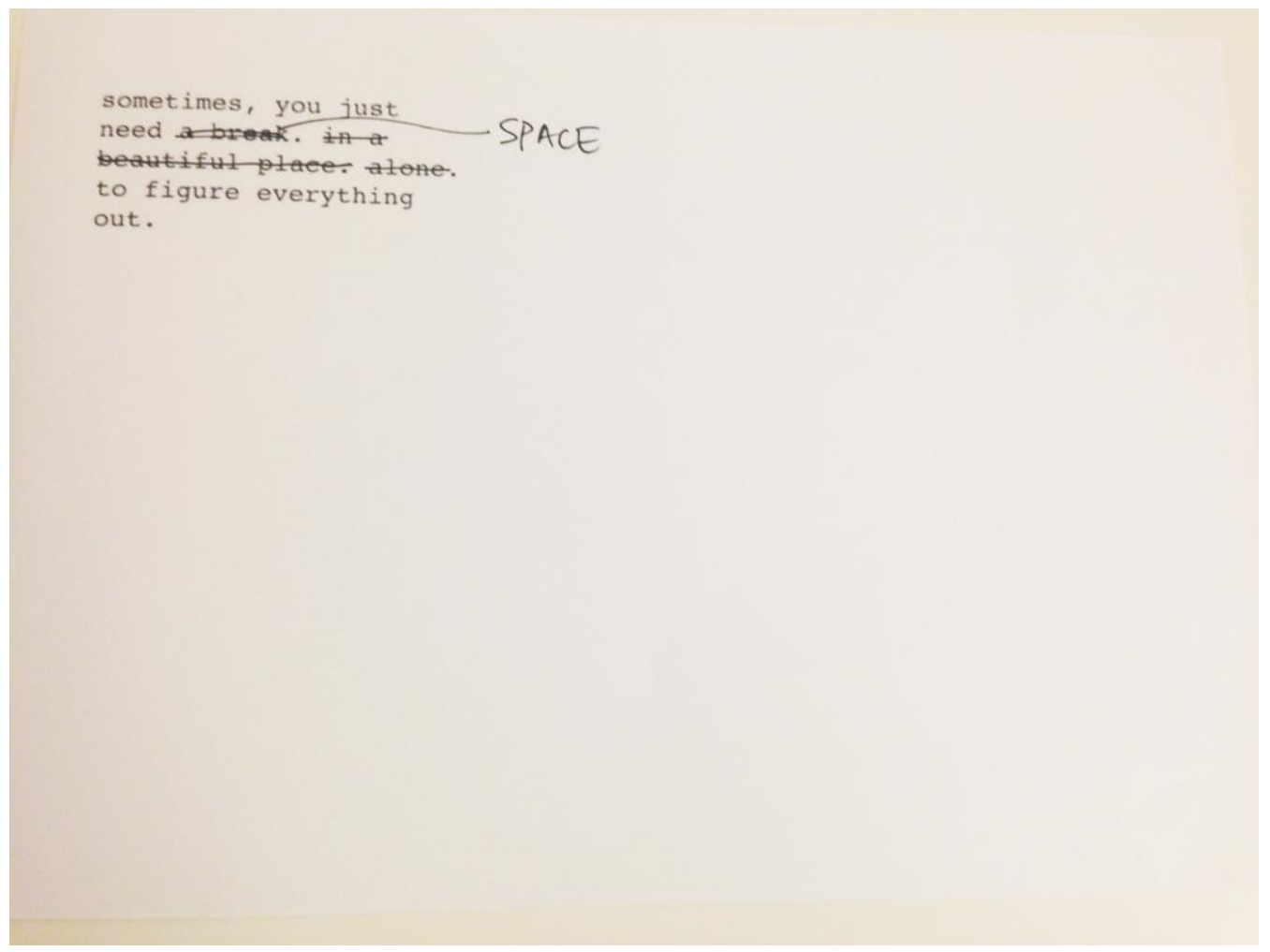

Figure 1. 'Sometimes...' Anon., edited by Rebecca Taylor, 2015

Together with research partner Mike Stead we were curious to listen to people and hear their concerns of the lack of green, social, outdoor space in Manchester's City

1 Judi Marshall, “Living Life as Inquiry," Systemic Practice and Action Research 12 (1999): 155-71, 
Centre. In May 2014, we facilitated conversations in local businesses and residents' apartments in the Northern Quarter (Fig. 2).

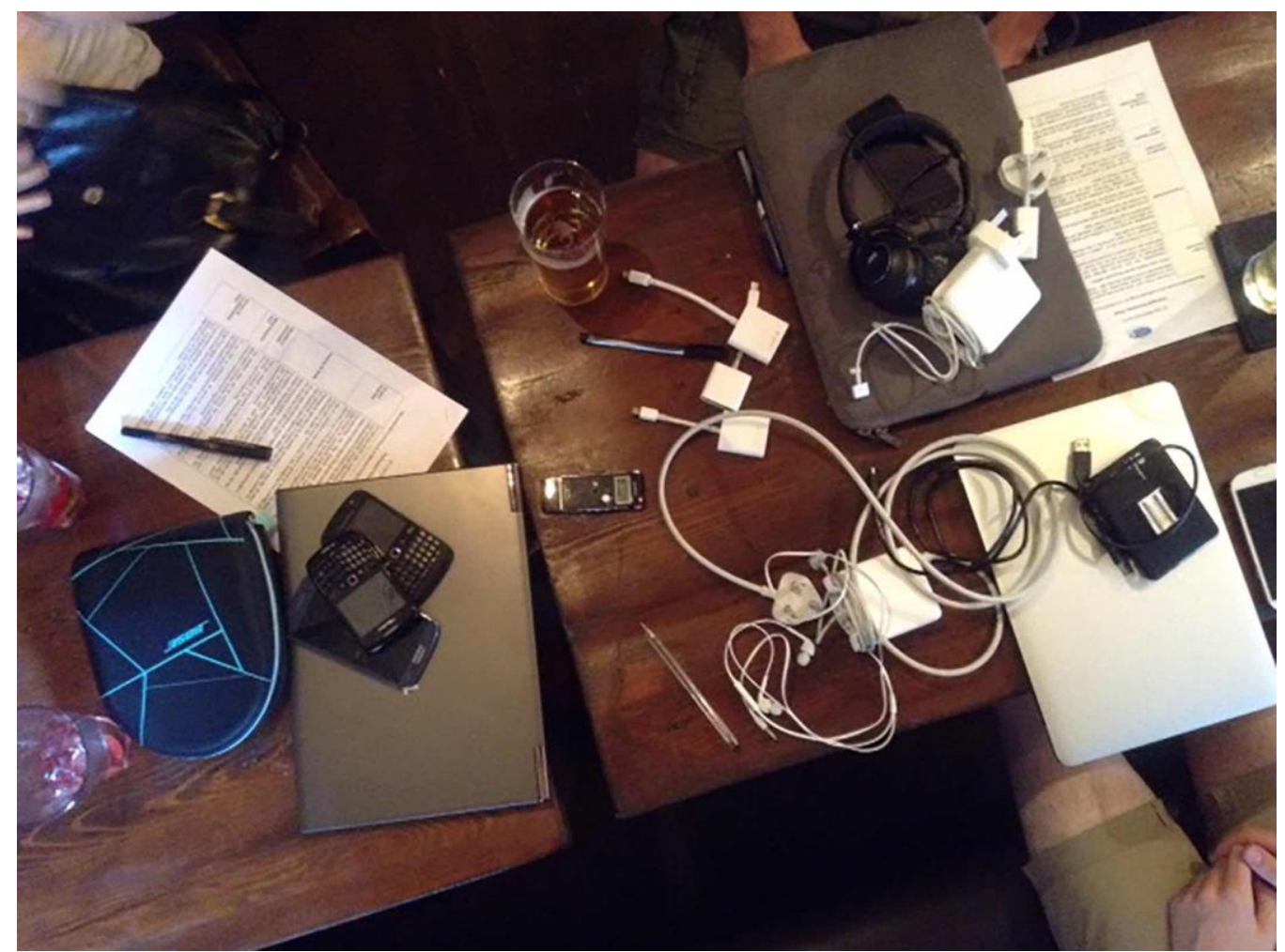

Figure 2. 'Have Conversations With...', by Rebecca Taylor and Mike Stead, 2014

We asked of those gathered at each conversation; 'If you were gifted a space in Manchester's Northern Quarter could you respond to a Speculative Challenge with the digital tools you have in your possession?' ${ }^{2}$ In August of that year we co-curated an exhibition that presented our findings as dialogical interactions ${ }^{3}-$ or as FuadLuke terms 'artifacts for activism' ${ }^{4}$ - and we challenged the motives and values of green, social space to people local to the area (Fig. 3).

http://www.jmarshall.org.uk/Papers/1999\%20Marshall\%20LivingLifeasInquiry.pdf. 2 R Taylor, M Stead, and N Dunn, "Participatory Citizens and Hybrid Cities: Imagining Green Spaces in Manchester's Northern Quarter," The UrbanIXD Symposium, 2014. ${ }^{3}$ Grant H Kester, Conversation Pieces, (Univ of California Press, 2004); Nirmal Puwar and Sanjay Sharma, "Curating Sociology," The Sociological Review 60, no. 1 (December 17, 2012): 40-63, doi:10.1111/j.1467-954X.2012.02116.x.

4 A Fuad-Luke, Design Activism: Beautiful Strangeness for a Sustainable World, 2009. 


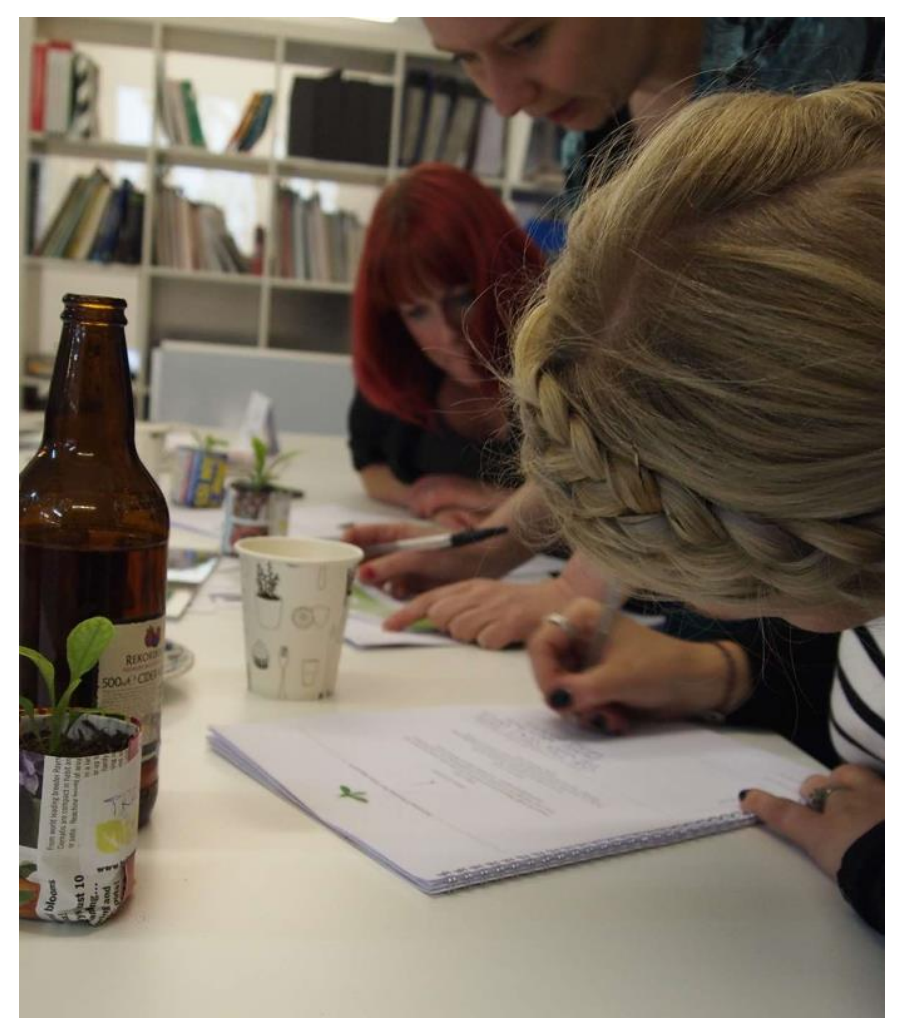

Figure 3. 'A Curious Event: Digging Deeper into Greening the Northern Quarter, Manchester', by Rebecca Taylor and Mike Stead, 2014

A conversation at the exhibition with Co-Founder and Partner of Architect, Interior Design and Building Management firm, The Sheila Bird Group, led to an invitation to occupy and co-design the rooftop space of 24-26 Lever Street and see what, if anything, could be achieved. The rooftop and the process of transforming the rooftop then became the focus of my doctoral research.

\section{Finding a Sense of Purpose in Doing Research through Design}

Positioned on top of the weathered and industry-beaten red brick buildings of Manchester's past are a host of dark asphalt rooftops, one just happens to now look 
a little different - it has been transformed into a green, multi-functional social space

(Fig. 4 and 5).

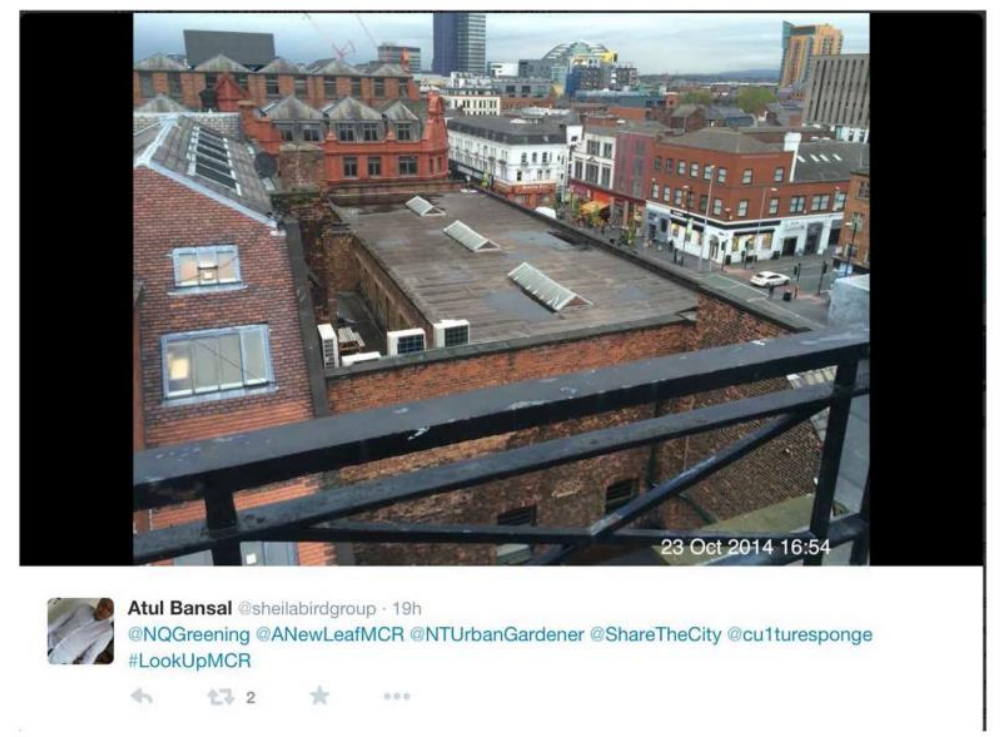

Figure 4. 'Before Tweet', by @sheilabirdgroup, Oct 232014

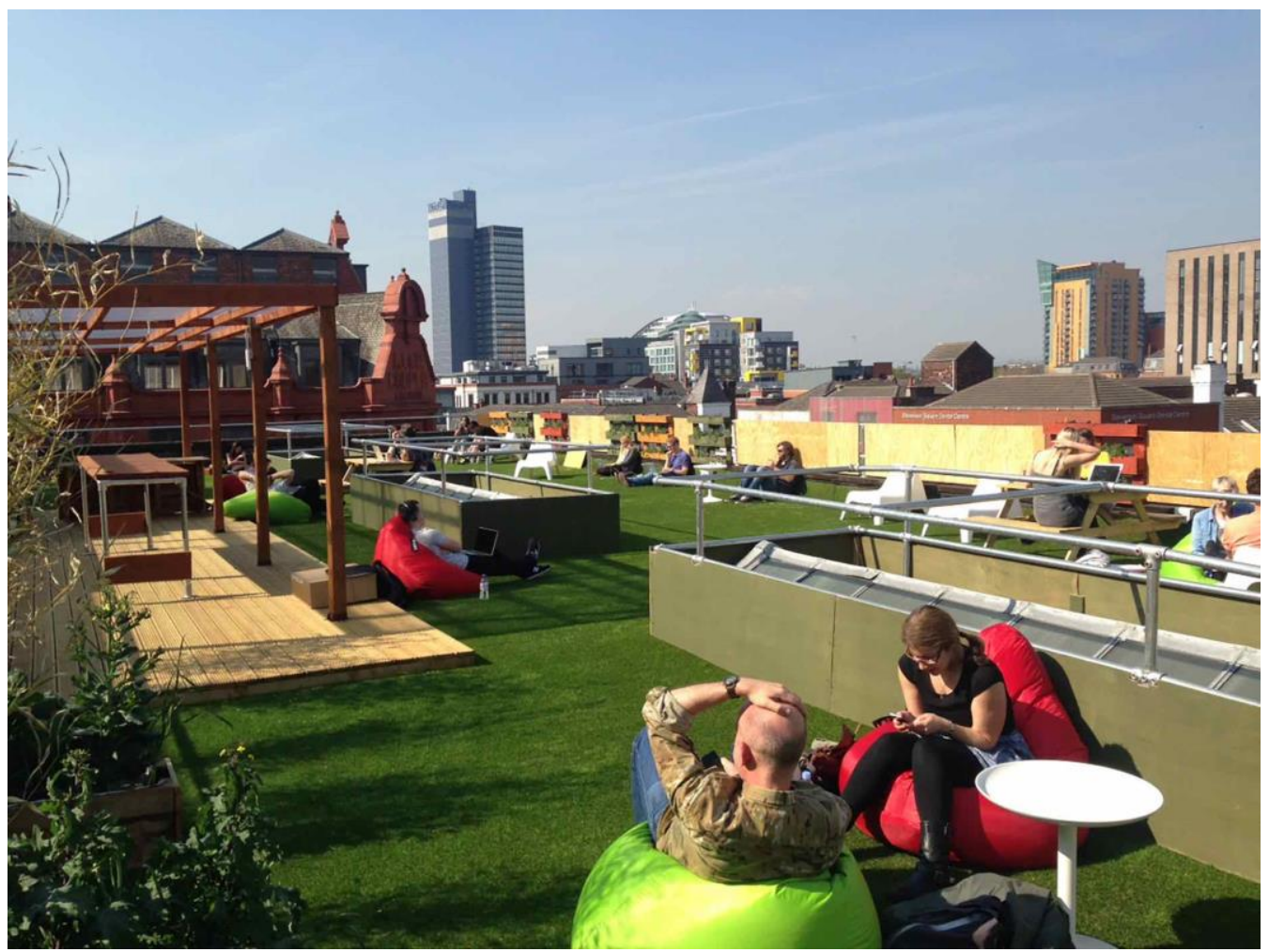

Figure 5. 'After Tweet', by @cu1turesponge, Apr 232015 
However, the visual aesthetics are only one element to The Rooftop Project, the roof top and the people involved underwent a curious 'design exploration' ${ }^{5}-$ a research through 'co-design process' ${ }^{6}$. By March 2015 the rooftop would be a green version of its grey former self, and an event entitled 'The Ladies Room' curated by Hayley Flynn (City Curator at The National Trust) emerged as an opportunity not to be missed (Fig. 6 and 7).

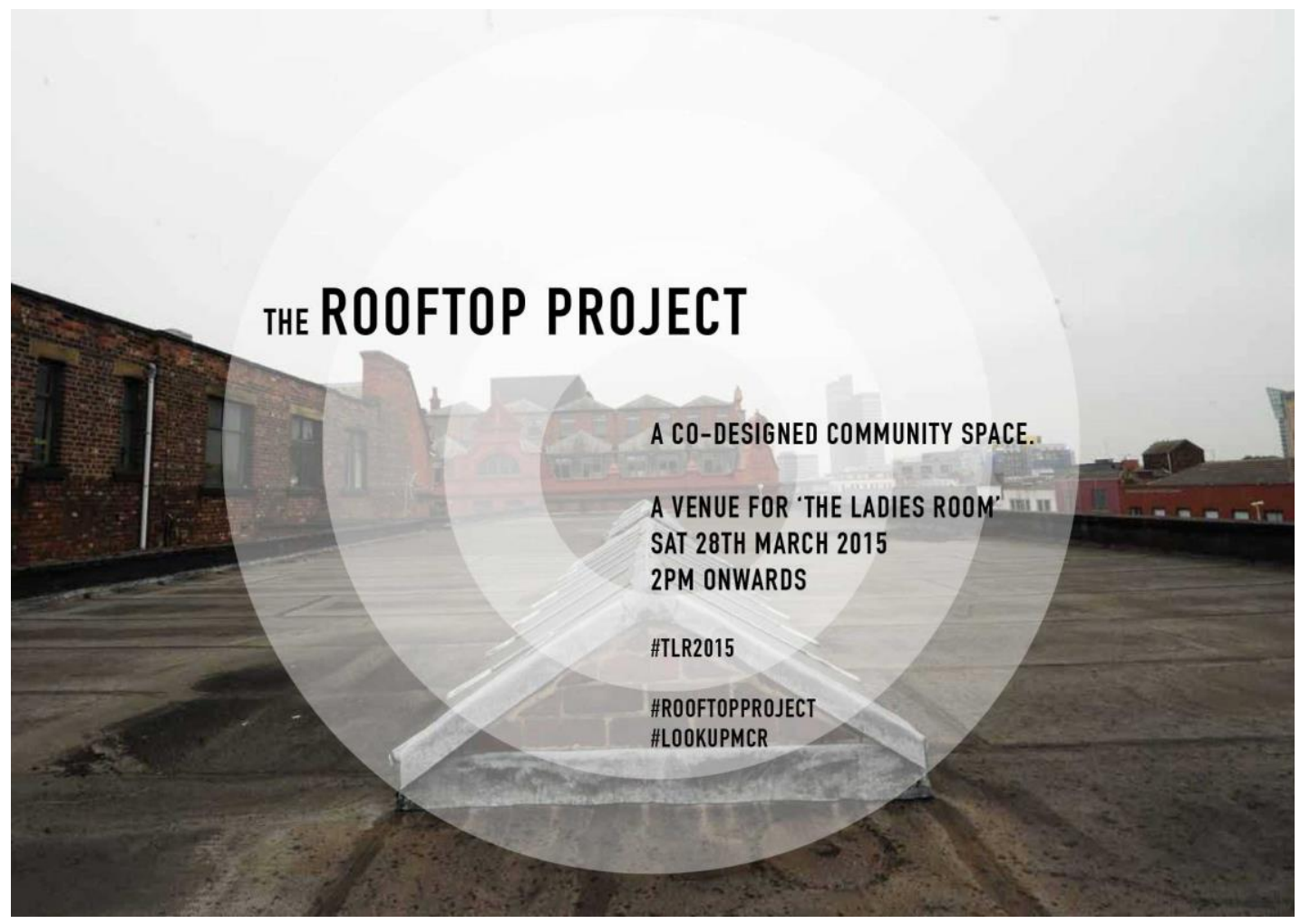

Figure 6. 'The Rooftop Project - A Venue for The Ladies Room', by Rebecca Taylor, 2015

\footnotetext{
5 Daniel Fallman, "The Interaction Design Research Triangle of Design Practice, Design Studies, and Design Exploration," Design Issues 24, no. 3 (July 2008): 4-18, doi:10.1162/desi.2008.24.3.4.

${ }^{6}$ EBN Sanders and P J Stappers, "Probes, Toolkits and Prototypes: Three Approaches to Making in Codesigning," CoDesign 10 (2014): 5-14, doi:http://dx.doi.org/10.1080/15710882.2014.888183; Elizabeth B N Sanders and Pieter Jan Stappers, Convivial Toolbox, (Bis Pub, 2012); Jesper Simonsen and Toni Robertson, Routledge International Handbook of Participatory Design, (Routledge, 2012).
} 


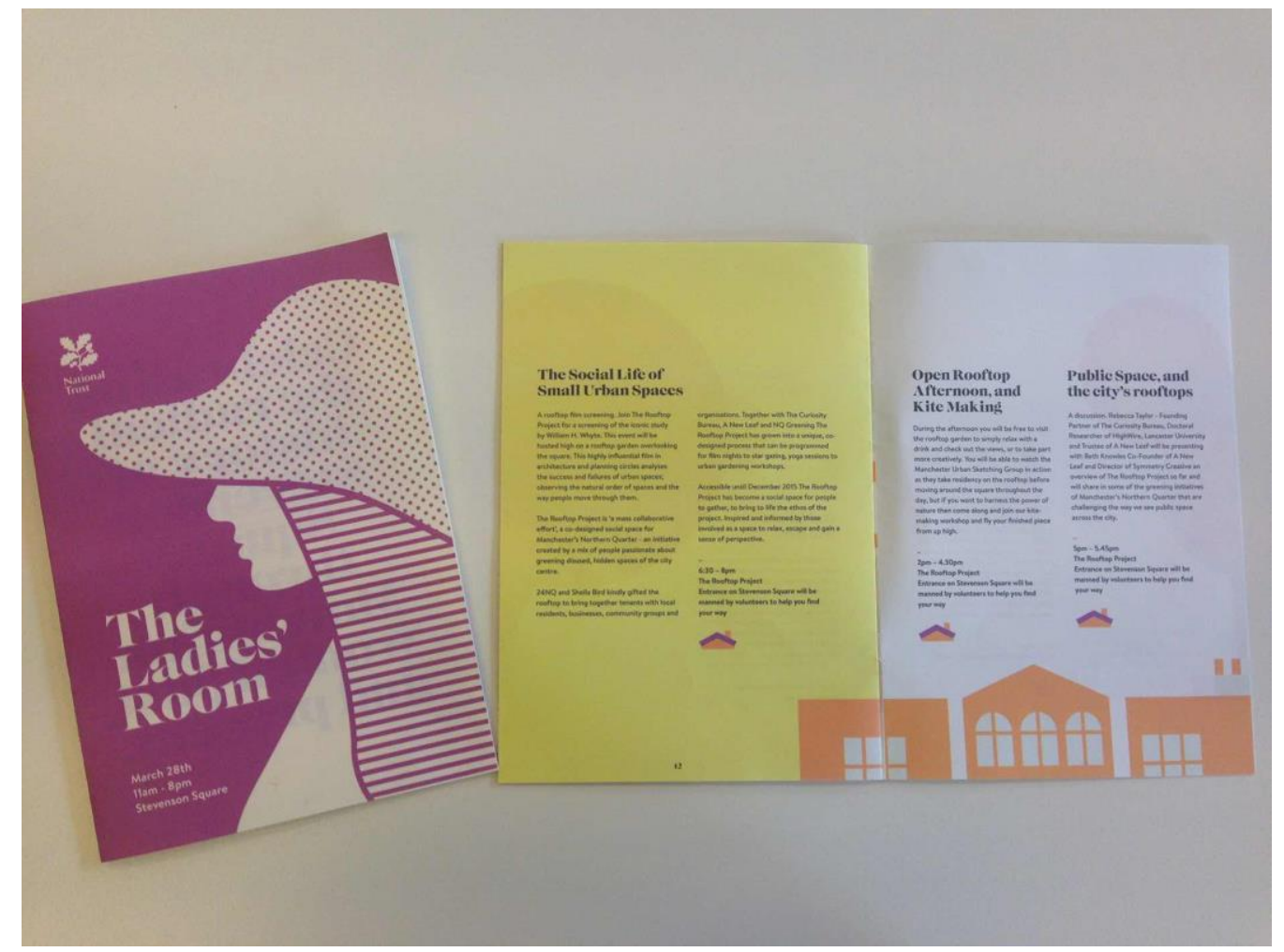

Figure 7. 'The Ladies Room Event', Neighbourhood, 2015

This would become the first opportunity for The Rooftop Project to become a platform to share in the stories and the co-designed social space for public programming. On Saturday $28^{\text {th }}$ March 2015 a number of curious spaces surrounding Stevenson Square became accessible to the public and shared in the stories of women who had made their mark in history campaigning for political changes. The event also asked who the activists are of today, how public space is being challenged, and how the square could be imagined in the future.

The event became an opportunity for the research to openly invite the public to see if the space would elicit 'features of experience'. Inspired by the paper 'Aesthetics and Experience-Centered Design' by Wright, Wallace and McCarthy, they connect Dewey's definition of 'experience' and have informed what I now term in my studies 
as 'features of experience' - "Dewey argues that sensation and emotion make the cement that holds experience together... In short then, the particular quality that marks out aesthetic experience is that it is creative, enlivening, and expressive, and involves the senses and values in inclusive and fulfilling activity that is considered worth engaging in for its own sake." 7 . The 'features of experience' - or, in other words, the emotions and feelings of experience shared by those involved in the codesign process, became the core element in the 'co-design brief' for the rooftop.

At The Ladies Room event I invited the public (of all ages) to document their 'features of experience' - to draw/write their feelings, emotions, things they experienced on the rooftop (Fig. 9).

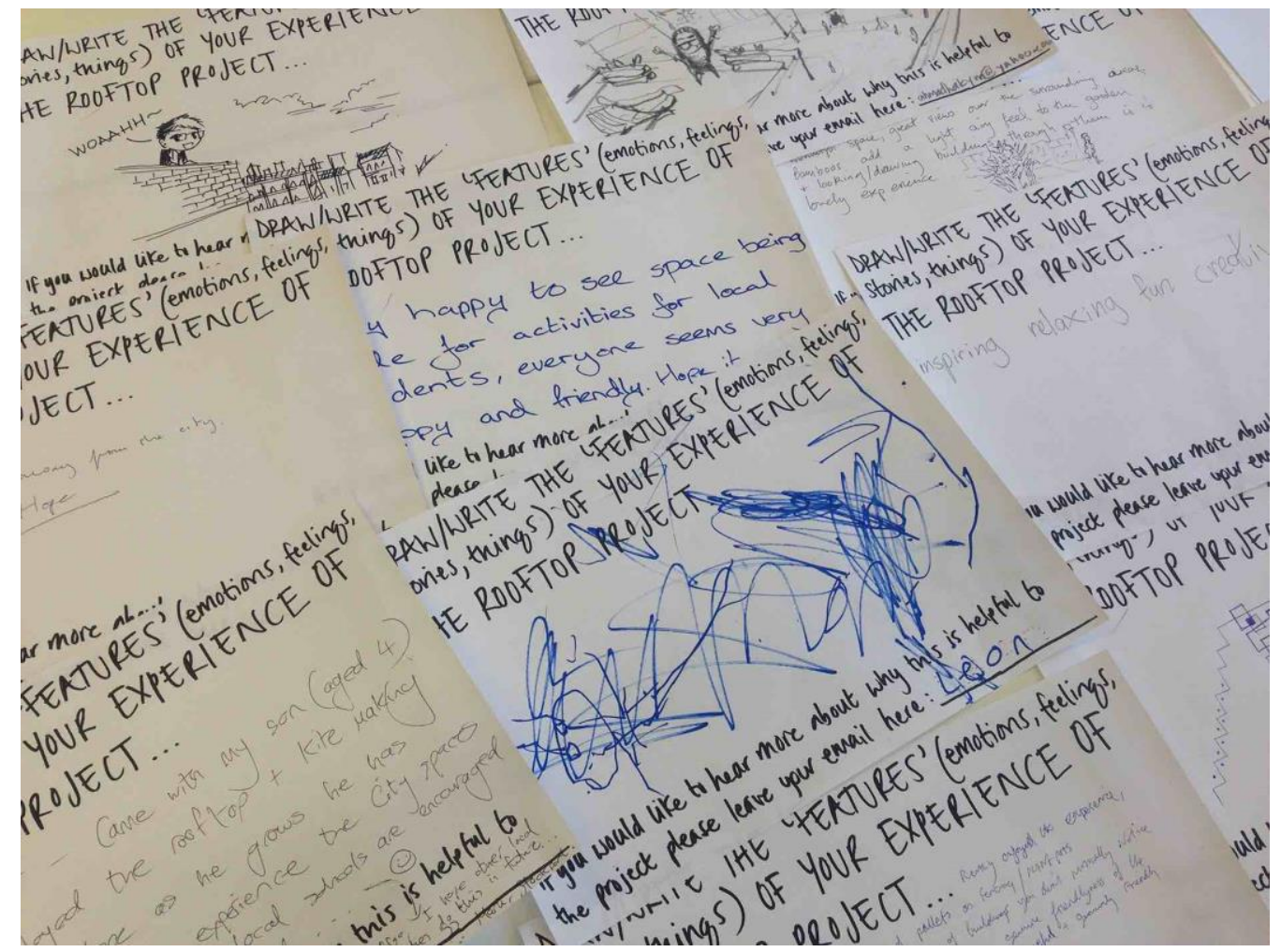

Figure 8. 'Features of Experience', by Rebecca Taylor, 2015

\footnotetext{
7 Peter Wright, Jayne Wallace, and John McCarthy, "Aesthetics and ExperienceCentered Design," ACM Transactions on Computer-Human Interaction (TOCHI) 15,
} 
As the physical transformation of the social space started to take shape and be used by people, it became apparent that the space indeed mirrored the features of experience shared by the community involved in its co-design, eliciting therefore; escapism, somewhere to relax, a sense of perspective, freedom, play, views, openness, spacelessness, community, freshness, fresh air, adventure. This was an important milestone in my practice-based research. The rooftop was now physically and emotively transformed. However, this was not the end but the continuation of the RtD process. It was not long before I would find myself asking how does the social space evolve?

Alongside physically making the rooftop into a green and social space, I found solace in literature surrounding being 'situated' ${ }^{8}$. I could now see more clearly how doing RtD is, as Suchman terms 'situated action' ${ }^{9}$. This enabled me to more confidently assert my perspective as a researcher, and I became more critically aware of the process in co-designing social space. I also began to assert a more considered, theoretical lens, that of 'sociomateriality' ${ }^{10}$. It was through this lens I could then

no. 4 (November 2, 2008, 18:2): 18, doi:10.1145/1460355.1460360.

8 Helen Kennedy et al., "Balancing the Potential and Problems of Digital Methods Through Action Research: Methodological Reflections," Information, Communication \& Society 18, no. 2 (October 15, 2014): 172-86, doi:10.1080/1369118X.2014.946434; Jesper Simonsen et al., Situated Design Methods, (MIT Press, 2014); David Coghlan and Mary Brydon-Miller, The SAGE Encyclopedia of Action Research, vol. 1, 2014; Lucy A Suchman, Plans and Situated Actions, (Cambridge University Press, 1987). 9 ibid.

10 Wanda J Orlikowski and Susan V Scott, "10 Sociomateriality: Challenging the Separation of Technology, Work and Organization," The Academy of Management Annals 2, no. 1 (April 1, 2009): 433-74, doi:10.1080/19416520802211644; Wanda J Orlikowski, "Sociomaterial Practices: Exploring Technology at Work," Organization Studies 28, no. 9 (September 1, 2007): 1435-48, doi:10.1177/0170840607081138; Lucy Suchman, Human-Machine Reconfigurations, (Cambridge University Press, 2006). 
explore a critical appreciation in The Rooftop Project of 'the inherent inseparability of the technical and the social' ${ }^{11}$.

The Rooftop Project has now entered its second season (Season One: March 2015October 2015; Season Two: March 2016-October 2016) and I have continued to document the way in which the social space (physical and digital) appears to be consumed and produced ${ }^{12}$ by those who work in the building and those who - on occasion - are invited up to the rooftop (Fig. 9).

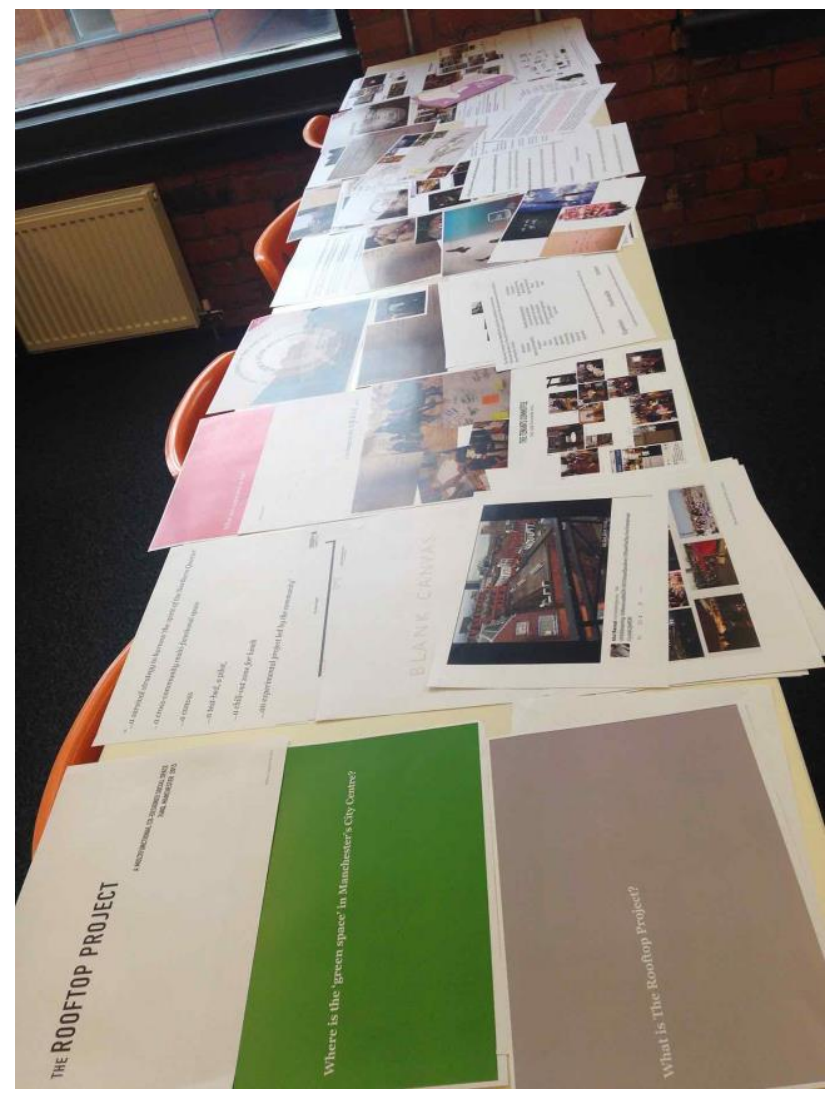

Figure 9. 'The Story of The Rooftop Project...', by Rebecca Taylor, 2015

11 Orlikowski, "Sociomaterial Practices: Exploring Technology at Work." 12 Henri Lefebvre, The Production of Space, 1993. 
Whilst the rooftop could be regarded as a private space, only accessible to those who work in the building, central to my doctoral research is for my practice to have a sense of purpose, inclusivity, and ways in which participation can be promoted and encouraged. 'Design Activism' ${ }^{13}$ has helped substantiate this sense of purpose, creating "the counter-narrative aimed at generating and balancing positive, social, institutional, environment and/or economic change" ${ }^{14}$. The RTD 2015 conference therefore came at a pivotal time in my research. I was doing research through codesign. Zooming out from the research, I was inquiring into co-design's parent discourse 'participatory design' ${ }^{15}$. Zooming in, and I was becoming more deeply inquisitive of the rhythm, temp and dynamics involved in doing co-design. For example, I grappled (and continue to do so) with the responsibilities that emerge of the role adopted by the designer and the researcher (or vice versa).

As The Rooftop Project has unfolded I have gained an awareness of the need for designers and researchers to be more inquisitive of their own sense of responsibility. I have realised that through designing experience, I too have been immersed with those participating in the RtD project and have therefore been experiencing design. This overarching concept exposes in my doctoral inquiry a two-way dialogical interaction: designing experience <> experiencing design. It is in being highly reflective (Fig. 10) and immersed in this methodological contribution that multiple design-led practices have emerged and, more importantly, in doing RtD the

\footnotetext{
13 Fuad-Luke, Design Activism: Beautiful Strangeness for a Sustainable World; A Thorpe, Architecture and Design Versus Consumerism: How Design Activism Confronts Growth, (Routledge, 2012), doi:10.4324/9780203119518.

14 Fuad-Luke, Design Activism: Beautiful Strangeness for a Sustainable World. 15 Sanders and Stappers, Convivial Toolbox; Simonsen and Robertson, Routledge International Handbook of Participatory Design.
} 
methodology has demonstrated the value in being curious and open to multiple ways of seeing and doing 'design'. For example, the 'design-led practice' to have emerged from The Rooftop Project has included; design activism ${ }^{16}$; design exploration ${ }^{17}$; and critical design ${ }^{18}$

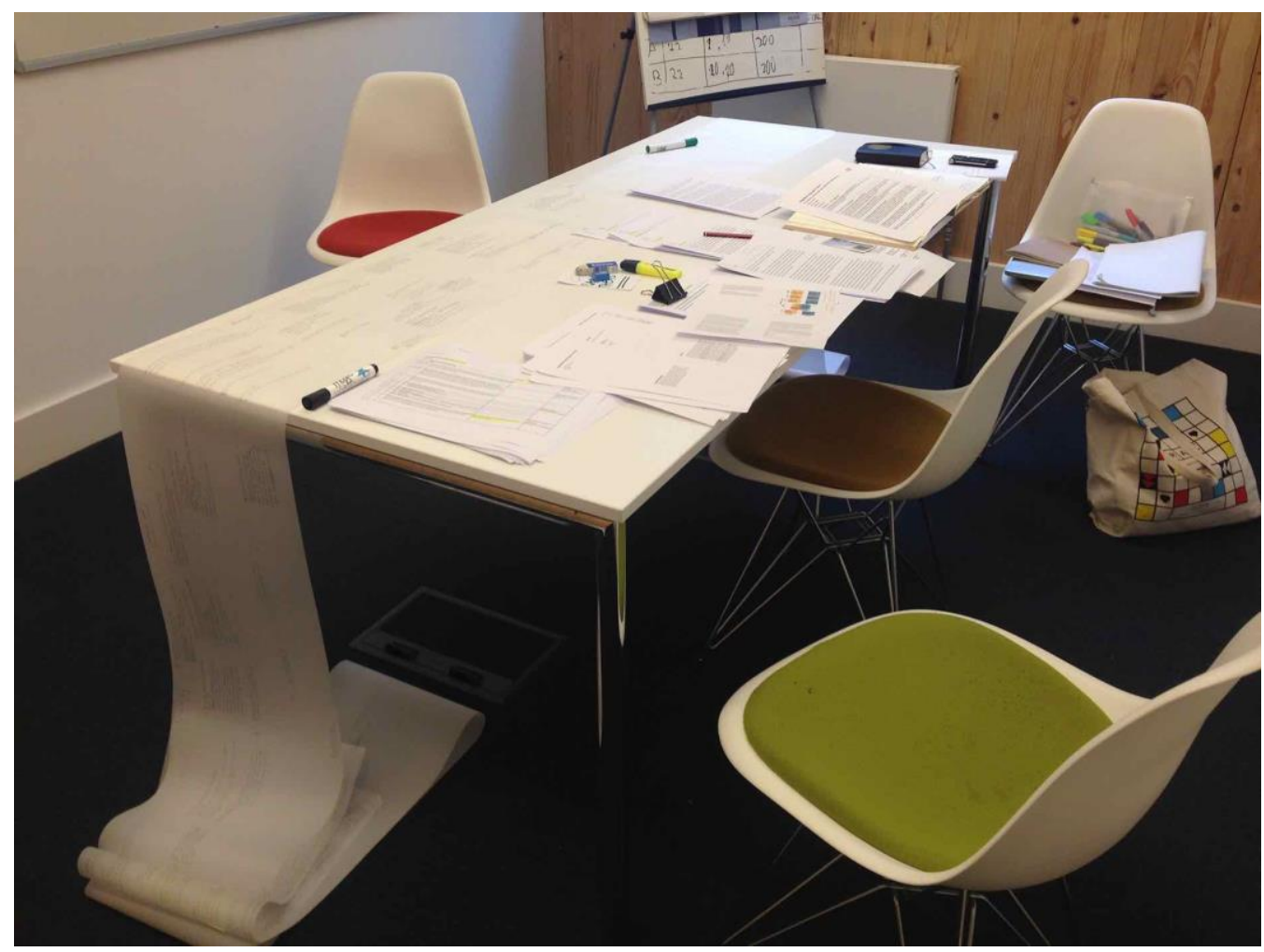

Figure 10. 'Doing Research through Design', by Rebecca Taylor, 2015

In being aware of my role as researcher through (experiencing) design $<>$ designer (experiencing) through research, I was keen to attend RTD 2015 and see the artifacts as examples of what perhaps should be seen as 'best practice'. Would I be able to identify with others' interpretation of this role as designer/researcher? What would their artifacts say of their experiences of RtD? There were a number of points of

16 Fuad-Luke, Design Activism: Beautiful Strangeness for a Sustainable World. 17 Fallman, "The Interaction Design Research Triangle of Design Practice, Design Studies, and Design Exploration."

18 Anthony Dunne and Fiona Raby, Speculative Everything, (MIT Press, 2013). 
interest that became prevalent to me during and upon reflection of my experience at RTD 2015. Below I have attempted to articulate three features of my experience that I believe also raise further questions for the RtD community as we determine a more cohesive methodology in practice.

\subsection{Designing Experience}

In Durrant et al.'s article ‘Developing a Dialogical Platform for Disseminating Research through Design" the authors describe the format they have provided as " $a$ descriptive, experience-centered account of composing a new international conference $\left.{ }^{\prime 19}\right)$. This description allows me to stretch more broadly the music metaphor and suggest that the features that emerged for me in experiencing the composition of the conference also embodied tempo and rhythm. Designed knowingly or unknowingly into the composition of the conference, I found this consideration to be particularly useful. For example, I felt gently encouraged to navigate through the three days at my own tempo - my own pace of thinking - and yet not lose sight of where I was being invited to next.

${ }^{19}$ A Durrant, J Vines, J Wallace, and J Yee, "Developing a Dialogical Platform for Disseminating Research Through Design," Constructivist Foundations, 2015, 414. 


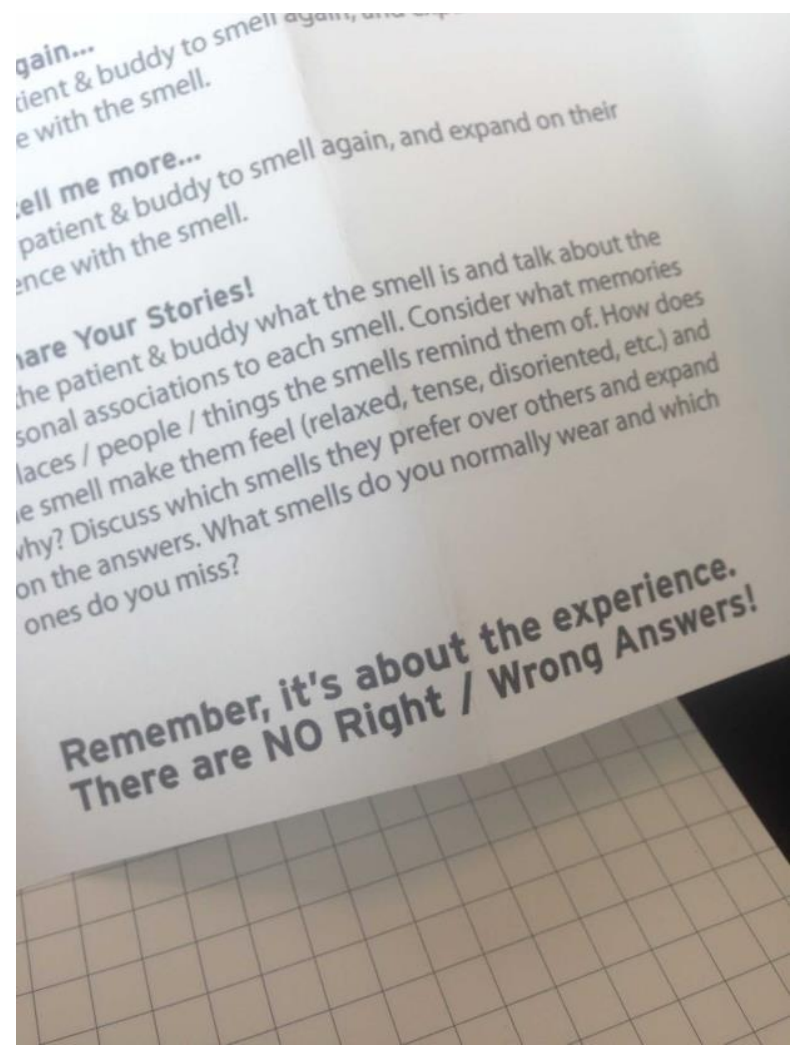

Figure 11. 'Being Reminded...', by Rebecca Taylor, 2015

I opted to attend the Town Hall meeting on day three. The meeting itself, I believed reflected the ethos of the conference - a safe space and an open forum for discussion. Someone commented on how "It's nice to have a stake in the design of experience" (misc. taken from my notebook). I found the composition of the conference program as a whole constructively disruptive and by making time for us to reflect on our individual and social experiences I felt I was witnessing what I consider integral to sustaining a holistic experience - a sense of mindfulness of experience, or a mindful experience design. Liz Edward's reflection, who as a contributor to RTD 2015, said the conference organizers "set the supporting tone and the ethos that emphasized authentic concern for the artifact and a genuine desire for a different kind of conference experience that valued research derived 
from practice." ${ }^{20}$ ). It was through having the emphasis placed on inviting people to experience the content, the artifacts, that I sensed the composition removed what I would call a self-congratulatory hierarchy - a common occurrence in more conventional conferences. It is refreshing to see the artifacts remain in the spotlight inviting people to be curious of the content, inquisitive and open to listening to the experiences of those I consider 'gate-keepers' of the artifacts.

\subsection{Walking a fine line with Nelly Ben Hayoun}

This leads to my reflection on the opening provocation by Nelly Ben Hayoun, a designer of experiences that unapologetically teases chaos and disruption. I welcomed the high-energy kick-start to the conference, Ben Hayoun sparked my curiosity in 'making experience' and I observed how she projected a fearless tone of voice to embark on a quest to disrupt and cause chaos. She designs experiences that I consider to walk a fine line between being disobedient ${ }^{21}$ and disruptive for disruptive sake, versus being considerate of the responsibility of the designer, whom she believes "we are not here to come up with the solution, but to question things, challenge things". Some may have conflicting views; I suggest we pose the question; should 'we' have responsibility of others' curiosity and consumption of experience? Ben Hayoun admits being fearless of conflict, saying, "I see conflict as part of innovation" and by applying chaos as a method of public engagement she admits her process is "total bombardment".

\footnotetext{
20 ibid. 416

21 G Grindon and C Flood, Disobedient Objects, 2014.
} 
Ben Hayoun has challenged my perceptions of designing experience by presenting her fearless process of teasing chaos and disruption, and her methodologies have prompted me to ask, what is the responsibility of the designer/researcher? Does 'being mindful' of designing experiences <> experiencing design matter to the future of RTD conferences and RtD methodology?

\subsection{Good vs Glory}

RTD successfully focused my attention on the artifacts and it was this focus that triggered a connection for me to consider the whereabouts of the designer's ego. It has also been a point of interest that has emerged from the process of co-designing the social space on the rooftop and it begs the question, how much of what we design is for good or glory, and does revealing and presenting artifacts also reveal and present our own agendas?

\subsection{Making connections with David Gauntlett \& Amy Twigger Holroyd}

On day two of RTD, David Gauntlett jointly presented a provocation with Amy Twigger Holroyd. For me this was an insightful presentation of what they believed to be prevalent when Making and Making a Difference: 1 . Social process (a moment of exchange); 2. Open-ended exploration; 3. Structuring through projects; and 4. A challenge. Hearing these principles sparked a deeper inquiry into my way of 'making space' and 'making a difference' through The Rooftop Project. I saw a connection between 'Making a Difference' and 'Doing Good', which emerged as an insight for further reflection through the co-design of the physical rooftop. By being immersed 
in Design Activism ${ }^{22}$ I find myself rationalizing ways of 'making a difference' and 'doing good'. This becomes a concern of mine amongst a community of academics is there a fine line between doing good for the campaign or cause in which you immerse yourself, and doing good for the glory of a unique project to bolster your portfolio and career prospects? I strongly believe this question, or versions thereof, should become of consideration to the RTD community because, whilst glory can exist without good being done, can good actually exist without glory? And if 'glory' is a criteria of success, a means for rewarding a designer, then how is 'glory' defined in an RtD project? There are multiple examples in the conference program of artifacts designed with doing (social) good in mind. Should we therefore prioritize the doing good' and make it a requirement? Or, would making it a requirement of RtD place emphasis on 'doing good' and therefore invite ambiguity - for instance, what would 'doing bad' look like? Can we set 'doing good' as a requirement of research? Will this tame a career of someone with an appetite for glory? Or, will it only illuminate tensions experienced of an unconventional conference? Should we be illuminating and deepening our critical thinking of 'good vs glory'? How are academics constructing coping mechanisms to manage these tensions?

\subsection{Materials \& Sociomateriality}

My most poignant experience of RTD 2015 was Tim Ingold's closing provocation. This was my first experience of Ingold and I soon became acutely aware that his philosophical approach was of tremendous importance for identifying my own

\footnotetext{
22 Fuad-Luke, Design Activism: Beautiful Strangeness for a Sustainable World;
} Thorpe, Architecture and Design Versus Consumerism: How Design Activism 
perspective as a researcher. The talk helped connect my thinking to doing RtD.

Ingold explained his rationale for 'making' and how 'the design of something goes on in the making'. When he described the creative process of a designer (or maker) as managing imagination and material he described, 'the flight of imagination and how it runs away with us', and how 'imagination is the thing that disappears and we struggle to keep up with it and take control of it'. He then proposed that it is indeed the material that slows our imagination, and how material engagements are weighty and hold us back as they weigh us down. In February 2014 I had undergone a practice-led, reflective deep dive ${ }^{23}$ with HighWire (my Centre for Doctoral Training at Lancaster University) and I related the group process to all Ingold was describing. I returned to the document (Fig. 12) and noticed, when designing the digital artifact to represent the process of our reflections I had applied the notion of 'line' and 'string'.

Confronts Growth.

23 Stuart Walker, The Handbook of Design for Sustainability, (A\&C Black, 2013);

Stuart Walker, Sustainable by Design, (Routledge, 2006); Stuart Walker, "Design and Spirituality: Material Culture for a Wisdom Economy," Dx.Doi.org.Ezproxy.Lancs.Ac.Uk 29, no. 3 (July 2, 2013): 89-107, doi:10.1162/DESI_a_00223. 


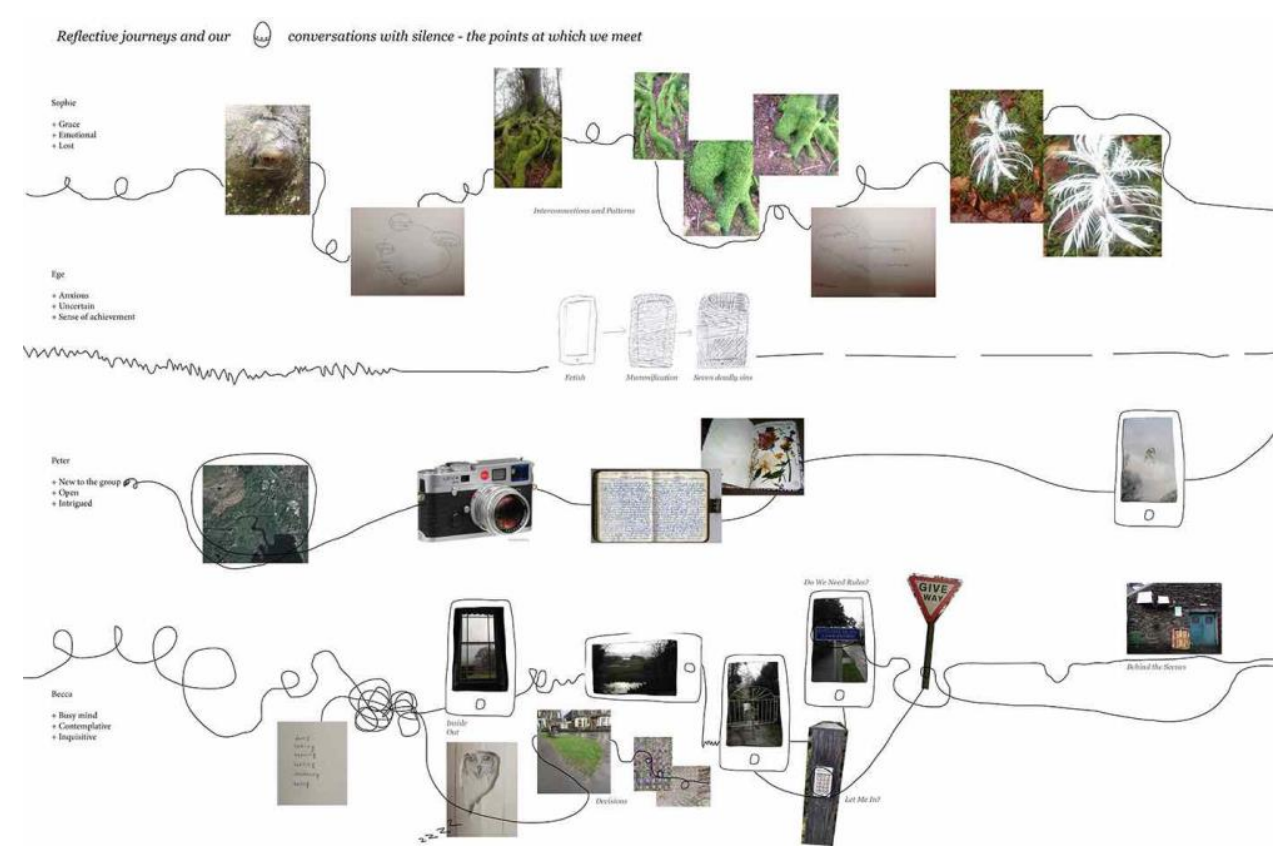

Figure 12. 'Doing Reflective Practice', by Rebecca Taylor, 2014

\subsection{Making my way forward with Tim Ingold}

I connected my experience of making an artifact of critical reflection with Ingold's considerations; 'making is the haptic process of feeling ones way forward in the world as opposed to the optical', which he says is based on the projection of the world. It became all too clear that in the design-led processes that have emerged of The Rooftop Project each design-led process (from design activism to co-design to situated design to critical design) consists of a palette of materials. I have since visited Ingold's chapter in his book, Being Alive (Ingold 2011), where he critiques 'Materials against Materiality' and cites concepts of materiality such as Archaeologists, Christopher Tilley's study of stones and his recognition of 'brute materiality', and Joshua Pollard's 'material character of the world...involved in human projects' ${ }^{24}$. Ingold says a paradox is inherent in both definitions and explains

24 Tim Ingold, Being Alive, (Taylor \& Francis, 2011 31). 
that, 'my purpose has been to escape from this oscillation, both by returning persons to where they belong, within the continuum of organic life, and by recognizing that this life itself undergoes continual generation in currents of materials.' ${ }^{25}$. I continue to seek clarity on this, especially as I am sensing a greater awareness in The Rooftop Project of the 'life itself [that] undergoes continual generation in currents of materials'. I have been encouraged by Ingold's proposition, and I have noticed how frequently he is cited across Information Systems and Participatory Design literature. Whilst Jones, Orlikowski and Scott do not explicitly discuss the weight of materials or materiality in sociomateriality ${ }^{26}$, it is in seeing sociomaterial resources ${ }^{27}$ emerge in The Rooftop Project that Ingold's proposition of the weightiness of material (both digital and physical) has become a curious perspective for me. He has introduced a way of seeing a rhythm, of sorts, to people's imagination in the co-design process. It has also led me to ask of my research, could it be argued that materials feel at their most weighty when (individual and social) imagination slows to almost a stand still? Ingold has encouraged a deeper inquisitiveness in me of materials and materiality, which in turn encourages me to seek a better understanding of sociomateriality. The design and consideration therefore of RTD's program has evidently had a significant impact on my theoretical lens as a doctoral researcher. It has inspired me to ask, what materials exist in my practice? Does their weightiness affect the rhythm of people's imagination in/of the rooftop? And, does imagination assist in seeking a

\footnotetext{
25 ibid. 31

${ }^{26}$ M Jones, "A Matter of Life and Death: Exploring Conceptualizations of Sociomateriality in the Context of Critical Care.," MIS Quarterly, 2014; Orlikowski and Scott, "10 Sociomateriality: Challenging the Separation of Technology, Work and Organization;" Orlikowski, "Sociomaterial Practices: Exploring Technology at Work." 27 Simonsen et al., Situated Design Methods.
} 
means for dis-entangling sociomateriality as it emerges in the co-design, production and consumption of social space?

In this article I have shared the features of my experience and the connections made between experiencing RTD and doing RtD. In summary, I propose that as a community of designers responsible for 'experience' if we critically reflect on the multiple ways in which we are experiencing RtD we will reveal ways to improve how RtD is experienced. It has been through making these connections that I believe I have challenged a deeper critical reflection of my experiences and responsibilities as a design researcher. My overall experience of RTD 2015 has not only opened my mind to the possibilities of the breadth and depth of RtD, it has also assisted my practice and critical reflection when I am immersed in being, seeing and doing RtD.

\section{References:}

Coghlan, David, and Mary Brydon-Miller. The SAGE Encyclopedia of Action Research. Vol. 1, 2014.

Dunne, Anthony, and Fiona Raby. Speculative Everything, MIT Press, 2013.

Durrant, A, J Vines, J Wallace, and J Yee. "Developing a Dialogical Platform for

Disseminating Research Through Design." Constructivist Foundations, 2015.

Fallman, Daniel. "The Interaction Design Research Triangle of Design Practice, Design Studies, and Design Exploration." Design Issues 24, no. 3 (July 2008): 4-18. doi:10.1162/desi.2008.24.3.4.

Fuad-Luke, A. Design Activism: Beautiful Strangeness for a Sustainable World, 2009. Grindon, G, and C Flood. Disobedient Objects, 2014.

Ingold, Tim. Being Alive, Taylor \& Francis, 2011.

Jones, M. "A Matter of Life and Death: Exploring Conceptualizations of Sociomateriality in the Context of Critical Care.." MIS Quarterly, 2014.

Kennedy, Helen, Giles Moss, Christopher Birchall, and Stylianos Moshonas.

"Balancing the Potential and Problems of Digital Methods Through Action Research: Methodological Reflections." Information, Communication \& Society 18, no. 2 (October 15, 2014): 172-86. doi:10.1080/1369118X.2014.946434. Kester, Grant H. Conversation Pieces, Univ of California Press, 2004. Lefebvre, Henri. The Production of Space, 1993. 
Marshall, Judi. "Living Life as Inquiry." Systemic Practice and Action Research 12 (1999): 155-71.

http://www.jmarshall.org.uk/Papers/1999\%20Marshall\%20LivingLifeasInquiry.p df.

Orlikowski, Wanda J. "Sociomaterial Practices: Exploring Technology at Work." Organization Studies 28, no. 9 (September 1, 2007): 1435-48. doi:10.1177/0170840607081138.

Orlikowski, Wanda J, and Susan V Scott. "10 Sociomateriality: Challenging the Separation of Technology, Work and Organization." The Academy of Management Annals 2, no. 1 (April 1, 2009): 433-74. doi:10.1080/19416520802211644.

Puwar, Nirmal, and Sanjay Sharma. "Curating Sociology." The Sociological Review 60, no. 1 (December 17, 2012): 40-63. doi:10.1111/j.1467-954X.2012.02116.x.

Sanders, EBN, and P J Stappers. "Probes, Toolkits and Prototypes: Three Approaches to Making in Codesigning." CoDesign 10 (2014): 5-14. doi:http://dx.doi.org/10.1080/15710882.2014.888183.

Sanders, Elizabeth B N, and Pieter Jan Stappers. Convivial Toolbox, Bis Pub, 2012. Simonsen, Jesper, and Toni Robertson. Routledge International Handbook of Participatory Design, Routledge, 2012.

Simonsen, Jesper, Connie Svabo, Sara Malou Strandvad, Kristine Samson, Morten Hertzum, and Ole Erik Hansen. Situated Design Methods, MIT Press, 2014.

Suchman, Lucy. Human-Machine Reconfigurations, Cambridge University Press, 2006.

Suchman, Lucy A. Plans and Situated Actions, Cambridge University Press, 1987.

Taylor, R, M Stead, and N Dunn. "Participatory Citizens and Hybrid Cities: Imagining Green Spaces in Manchester's Northern Quarter." The UrbanIXD Symposium, 2014.

Thorpe, A. Architecture and Design Versus Consumerism: How Design Activism Confronts Growth, Routledge, 2012. doi:10.4324/9780203119518.

Walker, Stuart. "Design and Spirituality: Material Culture for a Wisdom Economy." Dx.Doi.org.Ezproxy.Lancs.Ac.Uk 29, no. 3 (July 2, 2013): 89-107. doi:10.1162/DESI_a_00223.

Walker, Stuart. Sustainable by Design, Routledge, 2006.

Walker, Stuart. The Handbook of Design for Sustainability, A\&C Black, 2013.

Wright, Peter, Jayne Wallace, and John McCarthy. "Aesthetics and ExperienceCentered Design." ACM Transactions on Computer-Human Interaction (TOCHI) 15, no. 4 (November 2, 2008): 18. doi:10.1145/1460355.1460360. 